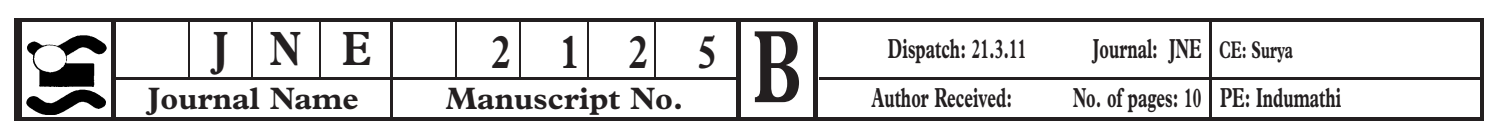

Journal of Neuroendocrinology 23, 1-10

REVIEW ARTICLE

(c) 2011 The Authors. Journal of Neuroendocrinology (c) 2011 Blackwell Publishing Ltd

\title{
Sex Differences in Adolescent Depression: Do Sex Hormones Determine Vulnerability?
}

\author{
E. F. G. Naninck*†, P. J. Lucassen ${ }^{*, 1}$ and J. Bakker ${ }^{+1}{ }^{1}$ \\ ${ }^{*}$ Centre for Neuroscience, Swammerdam Institute of Life Sciences, University of Amsterdam, Amsterdam, The Netherlands. \\ $\dagger$ Netherlands Institute for Neuroscience, an Institute of the Royal Netherlands Academy of Arts and Science, Amsterdam, The Netherlands.
}

\section{Journal of Neuroendocrinology}

Correspondence to:

Julie Bakker, University of Liege, Center for Cellular \& Molecular Neurobiology, Avenue de I'hopital 1, B36, Liege 4000, Belgium

(e-mail: jbakker@ulg.ac.be).

${ }^{1}$ Equal last authors.
Depression is one of the most common, costly and severe psychopathologies worldwide. Its incidence, however, differs significantly between the sexes, and depression rates in women are twice those of men. Interestingly, this sex difference emerges during adolescence. Although the adolescent period is characterised by major physical and behavioural transformations, it is unclear why the incidence of depression increases so dramatically in girls during this otherwise generally healthy developmental period. Although psychological and environmental factors are also involved, we discuss the neuroendocrinological factors determining adolescent vulnerability to depression. In particular, we address the role of sex steroids in mood regulation, hypothalamicpituitary-adrenal axis maturation and sexual differentiation of the brain, with a focus on hippocampal plasticity.

Key words: depression, sexual differentiation, adolescence, sex steroids, HPA axis.

\section{Equal last authors.}

(1)

doi: $10.1111 / j .1365-2826.2011 .02125 . x$

\section{Introduction}

Depressive disorders are a major health concern, an important cause of suicide and, because they affect more than 120 million people worldwide, they are expected to be the second leading cause of disability in 2020 (1). According to DSM-IV criteria, major depressive disorder is characterised by a depressed mood, a loss of interest or pleasure and low self-esteem. Other symptoms include: disturbed sleep or appetite, persistent feelings of sadness and irritability, poor concentration, low energy levels and suicidal thoughts (2). The severity and duration of these symptoms can vary strongly among patients. Depression not only severely affects the quality of life of an individual, but also has major repercussions on his/her family and social and work environment.

Several epidemiological studies have established the incidence of depression in women to outnumber men by a $2: 1$ ratio (2-4). Part of this pronounced sex difference may be contributed for by differences in help-seeking behaviour and symptom reporting between men and women, with women being more likely to seek treatment for psychological problems earlier (3), whereas men are more prone to cope with sadness or depressive symptoms through, for example, increased alcohol or drug abuse (3). Although this effect may be considerable, it is unlikely to fully explain the sex difference in the incidence of depression because this difference is not only observed in clinical studies, but also in nonclinical populations $(5,6)$.

Remarkably, the sex difference in the incidence of depression already emerges during early adolescence. Preadolescent boys and girls have a similar risk to develop depression, whereas, during adolescence, the incidence of depression strongly increases in girls and stays the same in boys $(2,7,8)$. Throughout adulthood, women have a $50 \%$ higher chance of experiencing an episode of depression than men (4). To date, the aetiology of this sex difference is poorly understood and it remains to be elucidated why it emerges during the adolescent period. In addition to providing a general overview of the main neuroendocrinological changes during depression, we will discuss putative neurobiological explanations for the emergence, during (early) adolescence, of sex differences in the incidence of depression. Although cultural, social and psychological factors are very important in the aetiology of depression, the main focus of this review is on the underlying biological factors.

\section{Depression in adolescents}

The prevalence of depression in adolescents is approximately 4-8\%. The consequences of adolescent depression vary from failure in society and social isolation to substance abuse and suicidal behaviour (9). As many as one-third of adolescents who suffer from 
depression attempt suicide (10) and some studies even report higher rates (9). Approximately $4-10 \%$ of depressed adolescents actually die as a result of suicide, which makes depression a major cause of death among adolescents $(1,10)$.

In general, the symptoms of adolescent depression are comparable to those of adult depression, although irritability rather than sadness appears to be more prominent in adolescents. However, depression in adults often shows a high comorbidity with substance abuse and sociopathy, whereas adolescent depression occurs more often in combination with other psychopathologies such as anxiety, conduct problems and learning disabilities $(2,10)$. In both adult and adolescent depression, recurrence rates are high. Furthermore, adolescents suffering from depression have a $40 \%$ chance of experiencing a recurrent episode later in life (10). When adolescent depression is left untreated, it can persist into adulthood and significantly increase the risk of developing other psychopathologies (11). However, it is important to note that the use of pharmacological antidepressants, such as selective serotonine reuptake inhibitors in adolescents has become surrounded by controversy, especially because the use of these drugs in adolescents has been associated with suicidality (suicidal thoughts, ideation or actions) during the first weeks of treatment (12).

Up until 20 years ago, evidence-based treatments for adolescents were practically unknown; nevertheless, antidepressants drugs developed for adults were administered to adolescents, even though their use may possibly interfere with brain maturation. For example, mice and rats that were treated with fluoxetine during the postnatal period (from postnatal days 4-21) showed increased anxietyand depression-related behaviour when tested drug-free in adulthood. However, similar effects did not occur as a result of fluoxetine-treatment during adolescence (13). In a study conducted by Norcross et al. [14], two different mouse strains were treated with clinically relevant doses of fluoxetine during the mouse adolescence' period (between 3 and 7 weeks of age). When tested drugfree in adulthood, these mice did not express any behavioural abnormalities and displayed normal fear-, anxiety- and stressrelated phenotypes (14). Regrettably, sex was not taken into account in these studies. By contrast, Hodes et al. (15) revealed that fluoxetine treatment in rats around puberty (between weeks 4 and 6 of age) did not affect cell proliferation in either males or females. However, increased hippocampal cell proliferation was observed in adult males as a result of fluoxetine treatment, whereas such effects did not occur in female rats at any age or stage of the oestrous cycle (16). It still remains to be determined, however, whether such sex differences in treatment responses are also present in humans.

The factors that contribute to the sex difference in treatment responses and incidence rate probably also contribute to the sex difference in depressive symptomatology. Although the personal experience of depression may appear largely similar for adolescent girls and boys, clear sex differences in depressive symptoms have been reported (17), with girls experiencing more guilt and bodily dissatisfaction, self-disappointment, feelings of failure and concentration problems than boys, whereas anhedonia, morning depressed mood and morning fatigue are more frequent in boys
(17). Adolescent girls also have a higher risk for recurrent periods than boys (3).

\section{Adolescence: a period of sexual differentiation}

Biological sex differences exist at the level of gene expression, hormone levels, anatomy and behaviour, with some of them already being present during early development. Sexual differentiation is determined as the process during which sex differences develop and diverge into male or female specific phenotypes (8) and starts with early sex determination. Adolescence is an important developmental period, during which both sexes undergo major physical, social and cognitive transformations $(8,18)$, and during which the divergence between the sexes becomes more prominent. Sexual differentiation is obvious with respect not only to well-known physical characteristics and behaviour, but also to the risk of developing psychopathology, and various psychiatric conditions including eating disorders, obsessive compulsive disorders, schizophrenia and depression all show clear sex differences in incidence rate. Notably, they have in common that their first manifestation often occurs during adolescence (19).

The neuroendocrine system plays a crucial role in the initiation and completion of these physical/biological alterations and psychosocial changes. The maturation of the hypothalamic-pituitary-adrenal axis (HPA) during early adolescence induces adrenarche (i.e. an increased production and secretion of adrenal steroids). This process precedes the rise in gonadotrophin-releasing hormone and results in increased release of the gonadotrophins luteinising hormone and follicle-stimulating hormone from the pituitary. In turn, these gonadotrophins stimulate the production of sex steroids by the gonads, causing a sharp increase in oestrogen levels in females and testosterone levels in males (20). The increased level of circulating steroids induces physical changes such as the rapid increase in growth induced by growth hormone levels and the development of secondary sex characteristics upon hypothalamic-pituitary-gonadal axis activity.

\section{Sexual differentiation of the brain}

In addition to the above mentioned obvious bodily changes, pubertal maturation also includes sex-specific changes in the neuronal systems that mediate cognition, emotion and motivation (21). Such neurobehavioural changes have been associated with increased risk-taking, sensation-seeking and reckless behaviour in adolescents (18). Little is known about the neuroanatomical changes that underlie these behavioural alterations, although the brain undergoes distinct morphological alterations during adolescence, including a linear increase in global white matter volume and an inverted Ushape type of development of region-specific grey matter volumes, in frontal, parietal and temporal brain areas $(19,22)$. These neurodevelopmental processes differ between adolescent boys and girls, with girls reaching peak grey matter volumes 1-2 years earlier than boys (21), parallel to the earlier onset of puberty in girls. Total brain size peaks also earlier in girls (at age 11.5 years) than in boys (at age 14.5 years) (21). On average, boys have a 9\% larger brain size 
than girls. However, this sexual dimorphism in total cerebral volume is not specific to puberty because it can already be observed in neonatal boys and girls and is consistently found in in vivo imaging studies in both children and adults $(8,22)$.

Sexual differences in the size of brain structures in adolescents have further been found in a voxel-based morphometry study; several brain regions were found to be larger in boys than in girls: the amygdala, putamen, thalamus, insula, rostral anterior cingulate and superior temporal gyrus, whereas the hippocampus, caudate nucleus, caudal anterior cingulated, middle temporal gyrus and inferior occipital gyrus are larger in girls (22). Studies in human adolescents have further indicated that amygdala volume increases significantly with age in men, whereas hippocampal volume increases significantly with age in women (21). The role of sex steroids in the development of these sex differences in volume during adolescence has received little attention in humans (19, 23). By contrast, numerous studies using animal models have shown that volumetric sex differences in the brain are established in response to changes in steroid hormone levels during development $(24,25)$. In rats, for example, neonatal exposure to testosterone and/or oestradiol affects the rate of apoptosis in certain brain nuclei and results in a greater volume of the bed nucleus of the stria terminalis (BNST) and a smaller volume of the anteroventral periventricular nucleus in males compared to female $(26,27)$. Also in humans, the role of sex steroid exposure during development appears to be prominent. For instance, a female-sized BNST, which is 44\% smaller in women than in men, does not appear to be established by exposure to sex steroids in adulthood but by sex steroid exposure during development (28). Thus, these studies, in addition to many others, have provided strong support for the organisational-activational hypothesis that was originally proposed in 1959 by Phoenix et al. (29). This hypothesis states that sex steroid exposure during prenatal and early postnatal development sexually differentiates the neuronal circuits (organisation), that become activated in adulthood by sex steroids, resulting in sextypical behaviours (30). Ever since the formulation of the organisational-activational hypothesis, the debate is still open regarding the hormone-driven sexual differentiation of the brain during various stages of development.

It is well-known that testosterone plays a crucial role in the sexual differentiation of the brain during critical periods of late prenatal and early neonatal development. The removal of testosterone in male rodents and nonhuman primates in neonatal development (via castration or the administration of anti-androgens) induces femaletypical behaviour, whereas testosterone administration to female animals within $24 \mathrm{~h}$ after birth generates male-typical behaviour (31). Testosterone has thus a masculinising and defeminising effect on the male brain, whereas the absence of testosterone induces feminisation of the female brain. In addition, ovarian steroids are assumed to play a role in feminisation (32). Removal of the ovaries in neonatal or prepubertal rats changes food-guarding behaviours, in typical 'male-like' behaviour, whereas adult ovariectomy has no effect. Treatment with oestradiol during puberty could prevent effects of prepubertal ovariectomy on the masculinisation of food guarding behaviour (30), suggesting that ovarian hormones play an important role in the feminisation of brain and behaviour during development.

The original view was that sex steroids have organisational effects during the perinatal period and activational effects in adulthood (29). However, new insights suggest that the organisational effects of sex steroids are not limited to a single critical sensitive period in perinatal development. They can also occur during adolescence $(8,30)$ when sex steroid exposure can modify the brain in a sex-specific manner (Fig. 1.) as shown in animal studies. In rats, for example, at least three sexual dimorphic brain regions have been identified: the anteroventral periventricular area (larger in females), the sexually dimorphic nucleus of the preoptic area and the medial amygdala (both larger in males) (33). A study by Ahmed et al. (34) showed that gonadal steroids maintained and accentuated these sexual dimorphic brain regions during adolescence. Male and female rats that were gonadectomised before puberty and subsequently injected with the cell-birth marker BrdU on three consecutive days during early puberty, showed lower numbers of BrdU-labelled cells 20 days later in all three sexually dimorphic brain areas, thereby eliminating the sex differences (34). Furthermore, Syrian hamsters that were castrated after the perinatal period of sexual differentiation, but before the onset of puberty, showed reduced male-typical social behaviour in adulthood compared to males castrated after puberty, although both groups received testosterone replacement in adulthood (35).

These studies have shown that, in contrast to the general view that sexual differentiation of the brain would take place before birth (in humans), or extend into the first postnatal week (rodents), the brain can also respond to gonadal hormones in a sex-specific manner later in development, during periods when a certain level of plasticity is still present (36). The question of whether sex steroid exposure during adolescence has solely activational effects or both organisational and activational effects as well, remains the subject of debate. However, studies in both primates (37) and rodents (36) indicate that completion of the sexual differentiation of the brain may require pubertal maturation. This suggests that puberty might be an additional organisational period in brain development.

Sex steroids are involved in several fundamental neuronal processes related to remodelling of the brain during adolescence, such as axonal sprouting and dendritic elaboration (important for the formation of new connections) and apoptosis and synaptic pruning (important for the removal of redundant neuronal tissue) $(19,34$, 38). Cell migration can be induced in vitro by administration of oestradiol, whereas administration of dihydrotestosterone fails to affect cell motility (38). Animal studies have further revealed sex differences in the effects of sex steroids on neuronal overproduction and synaptic pruning. Testosterone supports synaptic pruning in the male amygdala (39), whereas oestrogen suppresses neuronal overproduction in the rat prefrontal cortex $(39,40)$.

Taken together, these findings suggest a crucial role of sex steroids also in the control of neuronal formation, neuronal and synaptic selection, and hence in brain remodelling, during rodent adolescence. So far, in only a few studies, similar effects of sex steroids on brain structure have been found in boys and girls during puberty. Peper et al. (22) have shown higher oestradiol levels in 
(A) Sexual differentiation of the brain:

Sexual differentiation of the brain:

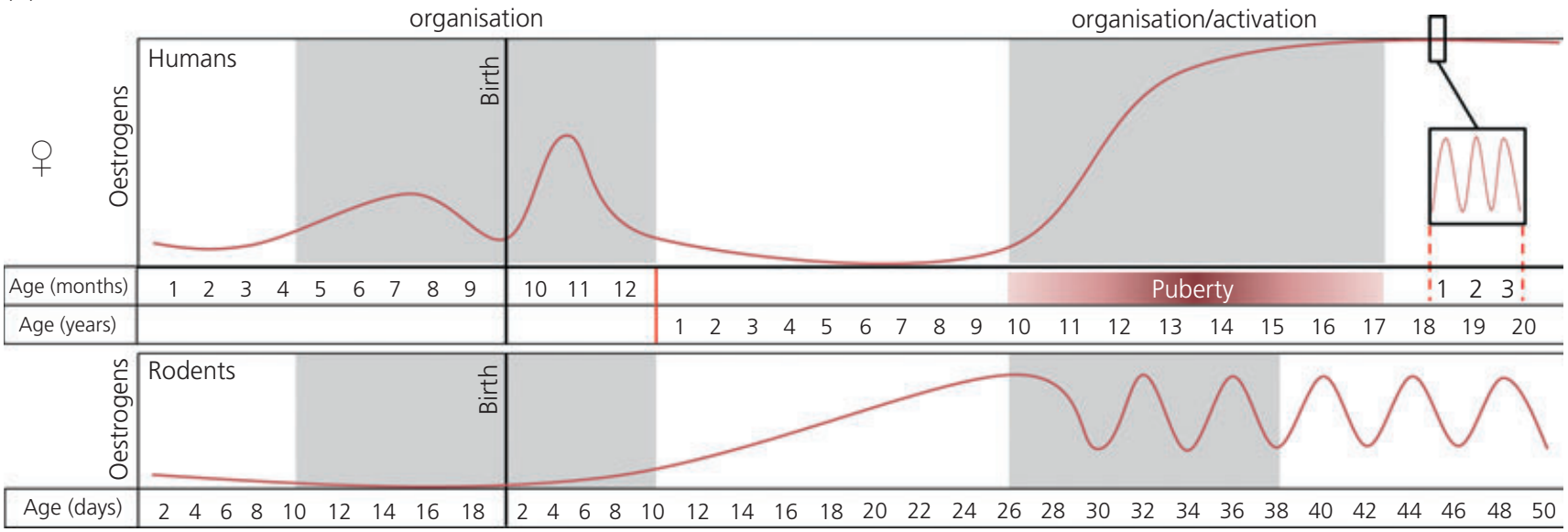

(B)

Sexual differentiation of the brain:

Sexual differentiation of the brain: organisation organisation/activation
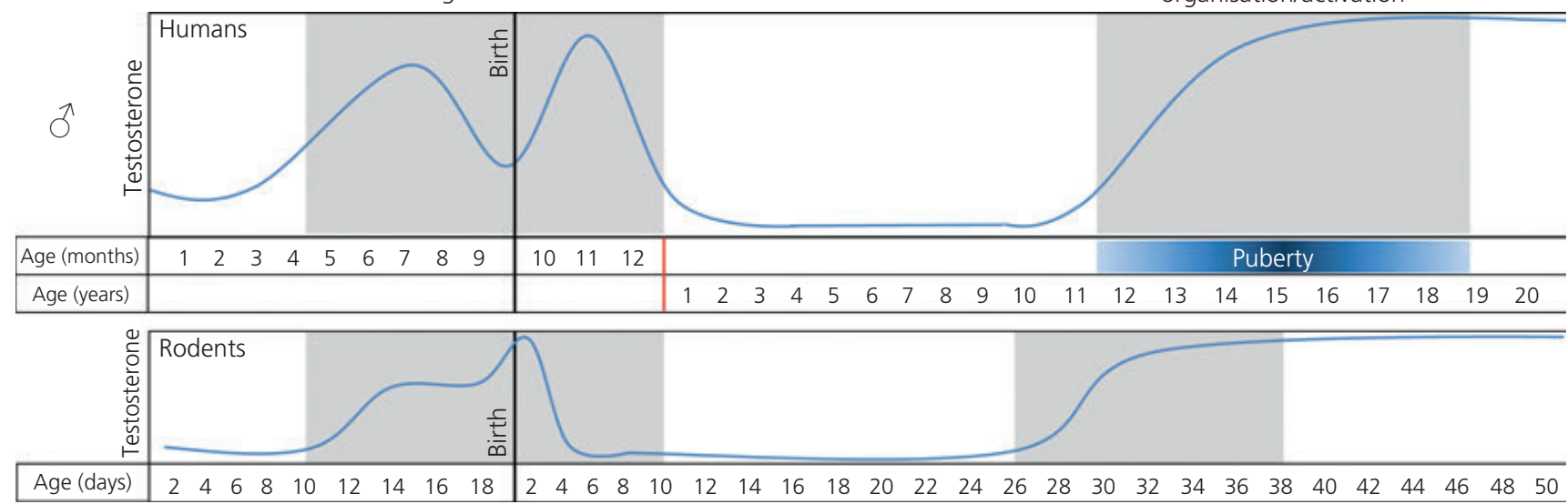

Fig. 1. Sex steroid expression during development.

adolescent girls to be linked to a smaller global grey matter volume, whereas higher levels of testosterone in boys corresponded with a larger grey matter volume. Furthermore, increases in cerebral white matter volume that occur during adolescence are associated with elevated levels of luteinising hormone (22). However, the precise relationship between sex steroid levels and sex differences in brain structure in human adolescents remains poorly understood.

Insight into the biological characteristics that appear during adolescence and that distinguish the male from the female brain will provide a better understanding of the sex-specific expression of psychopathologies and its aetiology. To better understand the emergence of sex differences in depression, we should consider risk factors involved in the aetiology of this disorder, including stress exposure and alterations in sex steroid levels, which are discussed below.

\section{Biological basis of depression}

Depression is a multifactorial psychiatric disorder and its risk is determined by a complex interplay of social, environmental and biological factors, including genetics, stressful experiences and hormonal actions on the brain. Although extensive research has generated a variety of theories on the biological basis of depression, the precise biological mechanisms underlying depression remain unknown. Part of the difficulty (as with so many psychiatric disorders that result from gene-environmental interactions) is the lack of an obvious neuronal or biochemical substrate and/or good animal models for the clinical condition. In 1965, Schildkraut (41) proposed the monoamine hypothesis, a biochemical theory that states that depression is caused by a functional deficit in monoamine transmitter regulation, which causes a disturbed noradrenalin and serotonin transmission that would induce depressive symptoms. Indeed, evidence exists to show that similar transmitter deficits are also involved in adolescent depression (42). A study by Hughes et al. (43) revealed that children and adolescents (between the ages of 7-17 years) suffering from depression had the lowest blood levels of 5-serotonin compared to age-matched controls and agematched patients with other behavioural disorders. In addition, the effectiveness of several drugs affecting brain monoaminergic transmission in alleviating symptoms of depression in adolescents is in line with this theory (10).

However, this general theory fails to explain why the clinical response to antidepressant drugs takes several weeks to develop in 
most patients, whereas the plasma levels of these drugs are elevated within hours following administration. Currently, therapeutic effectiveness of antidepressant drugs are no longer considered to solely result from rapid biochemical effects on neurotransmission but are assumed to involve slower structural adaptation in the brain, and part of the therapeutic effects could, for example, be mediated by drug-induced changes in dendritogenesis and/or neurogenesis (44-46). Novel theories on the biological basis of depression suggest that disturbances in neuronal or structural plasticity form a crucial component of depression, as well as of the mechanisms underlying antidepressant drug action $(44,45)$. The structural plasticity hypothesis states that structural networks involved in mood regulation are disturbed in depression (44).

\section{Hippocampal plasticity}

The hippocampus, together with the amygdala and prefrontal cortex, is an important brain structure in the aetiology of depression. This brain region is crucially involved in spatial and emotional learning and memory. It is also important in the regulation of the HPA axis, which plays a key role in controlling the neuroendocriene feedback of stress hormones. (47). In almost one-half of all depressed patients, the HPA axis is hyperactive (48) as is clear from elevated plasma cortisol levels, increased corticotrophin-releasing hormone $(\mathrm{CRH})$ and vasopressin expression in the hypothalamus and increased rates of dexamethason nonsuppressors among depressed patients $(48,49)$. Notably, hippocampal anatomy is sexually dimorphic and represents a sensitive target for sex steroids because it is richly endowed with oestrogen and other steroid receptors $(9,22,44)$. Despite this sensitivity and the strong HPA activation in a majority of patients, not many severe pathological changes are found in the hippocampus in depression (49-51), except for some alterations in structural plasticity $(52,53)$. Nevertheless, hippocampal volume reductions (10-15\%) are commonly found in depressive patients (54-58). It has been proposed that this reduction of hippocampal volume may result from alterations in neuronal plasticity induced by early life stress $(45,47,59)$, possibly in a sex-dependent manner (60-62). As possible explanations for the hippocampal volume reduction, stress-induced changes in hippocampal neurogenesis (63), cytogenesis, apoptosis or changes in glial cell numbers have been suggested to be implicated, whereas also changes in water metabolism or transport can be involved (45).

Chen et al. (59) recently reported reductions in hippocampal volume in healthy adolescent girls (between age 9 and 15 years) who are at high familial risk for depression compared to low-risk girls. Because none of the participants experienced an episode of depression, the study indicates that reductions in hippocampal volume may precede the onset of depression and may thus more likely represent a risk factor to develop depression rather than a consequence of the disorder, which also may be sex-dependent. Depression may develop not until stress is experienced. In rodents, exposure to early life stress was found to affect hippocampal structure in adulthood, resulting in lower hippocampal neurone and glia numbers $(64,65)$ and reductions in mossy fibre density $(66)$ and cell proliferation $(67,68)$. Interestingly, although some of these changes were transient, a sex difference was prominent in many studies $(60,69)$.

In humans, reductions in hippocampal volume particularly occur in women who were exposed to early childhood trauma (62). This underlines the potential importance of early life stress exposure, at least in women, for vulnerability to develop depression. Prenatal stress was further shown to reduce dentate granular cell number only in female offspring (70), whereas various other sex-related behavioural and structural differences have been reported (71), such as in various stress and HPA axis parameters (72-75). These findings indicate that early life stress (possibly via changes in hippocampus structure and function) forms a risk factor for the development of stress-related disorders in adult individuals (76-78) and particularly in women.

\section{Putative explanations for the emergence of sex differences in adolescent depression}

Although the aetiology of depression remains to be elucidated, current knowledge provides at least some biological explanations for the emergence of sex differences in depression during adolescence.

\section{Psychosocial theories}

Although the main focus of this review is on biological factors, one should not underestimate the importance of cultural, social and psychological factors in the aetiology of depression. Psychosocial explanations for the higher rates of depression in women include sex differences in stress coping, mother-child relationships and gender-specific expectations $(3,79)$. Another psychosocial explanation is based on the idea that women have, for social and cultural reasons, more problems in accepting the physical changes that occur during puberty than men $(3,79)$. It has also been suggested that adolescent girls have a predisposition to develop depression because of differences in social cognitive function such as rejection sensitivity (8).

These psychosocial variables may contribute to the higher depression rates in women, although validating these theories is difficult because a proper interpretation of the influence of psychosocial factors requires evidence that such a factor indeed accounts for a substantial portion of the observed sex differences in depression. It would be challenging to investigate how sex differences in social behaviour relate to sex differences in brain development, and very little is known about this. A better understanding of the neurodevelopmental processes underlying these behavioural sex differences may provide a key to understand the pronounced differences in the incidence of depression, and other psychopathologies during adolescence.

\section{Stress exposure}

Severe stressors such as harmful childhood experiences, including sexual abuse and sexual harassment, form predisposing factors for the development of depression and have been associated with 
reductions in hippocampal volumes (59). Sexual abuse has been associated with the emergence of sex differences in the susceptibility to depression because it is more frequent in girls and female adolescents than in boys and the overall rates of sexual abuse increase significantly for girls between the age of 10 and 14 years.

Another important factor in stress effects is the differential maturation of the HPA axis during adolescence. Various factors play a role in stress sensitivity but whether stress exposure has adaptive or maladaptive consequences is likely to depend on gender, the amount of stress and the developmental stage during which the stress is experienced (80). For example, neonatal rats show a lower HPA response to stress during postnatal day 3-14, a period referred to as the stress-hyporesponsive period (81). Adolescent development has also been associated with marked changes in stress sensitivity (80). Limbic and forebrain regions involved in $\mathrm{CRH}$-mediated HPA axis regulation and stress responsiveness, such as the prefrontal cortex, amygdala and hippocampus, continue to mature during adolescence (7). Basal levels of adrenocorticotrophic hormone (ACTH) and corticosterone are comparable between early adolescent (28 days of age) and adult rats (77 days of age) and increase in a similar way upon an acute stressor (a single 30-min session of restraint stress); however, stress hormone levels remain elevated 45-60 min longer in juvenile compared to adult rats, in both females and (82) males (83). Interestingly, treatment of juvenile male rats with testosterone, aiming to induce adult-like physiological testosterone levels, does not change the stress response towards an adult-like response, which indicates that further maturation of the HPA axis during puberty is essential to establish a more tightly-regulated stress response in adulthood (83).

The stress response upon repeated stress exposure (30 min of restraint per day for a period of 7 days) also differs between rats in early adolescence ( 28 days of age) and adulthood (77 days of age), with juvenile male rats showing a higher peak in corticosterone levels immediately after restraint but a faster return to baseline stress hormone levels (47). Interestingly, female rats do not show this marked hormonal response upon repeated stress (84).

Recent studies on the behavioural consequence of stress experienced during adolescence indicate that it induces anxiety- and depressive-like behaviour (80). For example, exposure to mild stressors during adolescence leads to increased depressive-like behaviour in the forced swim task, whereas exposure to the same stressor in adulthood has no behavioural effects (80). In addition, Tsoory and Richter-Levin (85) have shown that rats exposed to chronic variable stress during juvenility (27-29 days of age) or adolescence (34 days of age) show increased anxiety-like behaviour in adulthood. Furthermore, they demonstrate that helplessness-like behaviours are different between juvenile-stressed and adolescent-stressed rats, which might indicate that the exact age at the time of stress-exposure might be important in shaping the HPA axis (85).

In a recent study, Barha et al. (86) showed that chronic restraint stress in adolescent rats (30 days of age) alters basal corticosterone levels and hippocampal plasticity in adulthood in a sex-dependent manner. Chronic stress exposure during adolescence (consisting of $1 \mathrm{~h}$ of restraint stress every other day at unpredictable times for a period of 3 weeks), increased corticosterone levels 60 min after stress exposure in both sexes. However, only female (and not male) rats exposed to chronic adolescent stress have higher corticosterone levels in adulthood compared to nonstressed controls. Furthermore, in these adult female rats, cell proliferation and survival in the dentate gyrus of the hippocampus was decreased, whereas, in adult males exposed to adolescent stress, cell survival was slightly higher compared to controls (86). Taken together, these studies indicate that adolescence, similar to perinatal development, is a critical sensitive period for the effects of stress on brain modelling. Stress exposure during such sensitive periods of ongoing HPA axis maturation might programme the brain in a sex-dependent manner and therefore increase susceptibility to stress-related disorders under specific conditions later in life. However, stress during development does not always have maladaptive consequences. For example, early maternal deprivation is known to change HPA axis activity and neurogenesis in a sex-dependent manner in early adolescence. When studied at adult age, maternally deprived male, but not female, rats show poor spatial memory and reduced hippocampal long-term potentiation whereas emotional memory in a fear conditioning task and long-term potentiation under stressful conditions were strongly improved (60). Thus, stress during development appears to prepare the organism to perform optimally under similar stressful conditions in adulthood.

\section{Sex steroids interacting with the stress system}

Research in animal models has indicated clear sex differences in HPA responsiveness in adult animals, including higher levels of corticosterone and $\mathrm{CRH}$ in female rats. These sex differences are associated with sex steroid feedback regulation on the HPA axis (87). Ovarian steroids further up-regulate HPA activity in female adults. During pro-oestrus, the phase of the oestrous cycle in which oestradiol levels are the highest, basal $\mathrm{CRH}, \mathrm{ACTH}$ and corticosterone levels are elevated and $\mathrm{ACTH}$ and corticosterone increase more in response to stress than during other phases of the cycle. By contrast, ovariectomy reduces ACTH and corticosterone levels in adult rats, whereas oestrogen-replacement restores stress hormone levels (87).

In males, but not in females, oestradiol increases corticosteroidbinding globulin, probably protecting males to the excitatory effects of oestradiol on the HPA axis by decreasing the amount of free corticosterone (87). It has been shown that stress in adult female rats has dramatic effects on spine densities in the CA1 area of the hippocampus, especially during pro-oestrus when spine density is high. Although exposure to an acute stressor increases dendritic spine density (with approximately 30\%) and improves learning in adult male rats, exposure to the same stressor leads to a reduction in the amount of dendritic spines and impairs learning in female rats (88). Androgenised female rats, which were s.c. injected with testosterone within $24 \mathrm{~h}$ of birth, respond to the stressor similar as males: they show a $20 \%$ increase in spine density and learn better (89). The opposite effects of stress in androgenised females versus cycling females indicate that neonatal exposure to testosterone is important in programming stress responses in adulthood. Normally, pro-oestrous females have higher spine densities in the CA1 than 
males (88), and the finding that the increase in spine density during pro-oestrus is prevented by exposure to a stressor suggests that females are more sensitive to stress when oestrogen levels are high.

Although human adolescence represents a stressful period for both sexes, stress exposure per se might have a much greater impact on girls than on boys, especially because it has been shown that androgens inhibit hypothalamic CRH production. Furthermore, androgen replacement in the medial preoptic area in gonadectomised rats decreased corticosterone release upon a stress response (87). In summary, exposure to stress has different effects in adulthood than during the adolescent period, when maturation of the HPA axis is still ongoing. Regulation of HPA function by sex steroids might result in a hypersensitivity to stress in females, whereas males would benefit more from the protective effects of androgens.

\section{Sex steroids interacting with neurotransmitter systems}

Next to other sex steroids, oestrogen influences mood and behaviour $(4,5,42,79,90)$. Two different oestrogen receptor subtypes $(E R \alpha$ and $E R \beta)$ are expressed in the nervous system. In both sexes, $E R \alpha$ expression dominates brain regions that are important in the regulation of reproductive behaviour, whereas $\mathrm{ER} \beta$ expression levels are higher in brain regions that are involved in the regulation of mood, such as the hippocampus (4) and the BNST, a sexually dimorphic limbic brain region which is crucially involved in longterm, contextual fear responses and highly responsive to sex steroids (91). Studies in rodents have revealed that the $E R \beta$ receptor subtype is important in the modulation of depression-like behaviour in both sexes. For example, in ER $\beta$ knockout mice, depression-like behaviour is significantly increased. Furthermore, in gonadectomised wild-type mice, ER $\beta$ agonists were efficient in decreasing depression-like behaviour (4).

Depressive symptoms have been associated with low levels of oestrogen and drops in oestrogen concentrations, whereas high levels of oestrogen correlate with a positive mood (20). In the literature, reduced levels of oestrogen in women form a risk factor for depression (42). However, in adolescent girls, it is more likely that the sudden appearance of high oestrogen levels coinciding with an up-regulation of HPA activity (87) relate to negative mood in adolescent girls. Accordingly, negative mood in adolescents was shown to correlate significantly with a rapid increase in oestradiol levels (92). It is suggested that once brain and body become mature, they adapt to the new levels of circulating sex steroids. By then, decreases in oestrogen levels become relevant in affecting mood, for example in post-partum depression (20).

Furthermore, the initiation of cyclic fluctuations in sex steroid levels at adolescence has been reported to involve the emergence of depression in adolescent girls (42). In girls, the onset of menarche introduces monthly fluctuations in levels of gonadal hormones and gonadotrophins. Especially in periods of marked hormonal fluctuations, women have an increased risk to experience an episode of depression (4). Fluctuating levels of sex steroids at adolescence thus induces a major transformation in the hormonal levels in the the brain, to which the rest of the systems have to adjust (42).
To reveal a role for sex steroids in the psychopathology of depression, we must understand how sex steroids influence mood and behaviour. Sex steroids modulate mood by affecting neurotransmitter systems $(42,90)$ and the mechanisms by which oestrogen, progesterone and testosterone act on serotonergic-, noradrenergic-, dopaminergic and GABA-ergic neurones are increasingly understood. By activation of intracellular receptors, sex steroids modulate transcription of genes that encode for various proteins including synthetic and metabolic enzymes for neurotransmitters, neurotransmitter transporters and receptor proteins for neurotransmitters, neuropeptides and growth factors (90). Although sex steroids and neurotransmitter systems are linked in various ways, their interaction is complex and remains difficult to study, particularly regarding the behavioural effects of sex steroid-dependent neurotransmitter modulation.

In animal and (to a much lesser extent) in human studies, oestrogen effects on serotonin neurotransmission have been investigated and oestrogen is known to interact both with $5-\mathrm{HT}_{1}$ and 5$\mathrm{HT}_{2 \mathrm{a}}$ receptors. Ovariectomy decreased the expression of these receptors, as well as receptor binding. Strikingly, these effects can be reversed by oestrogen replacement (5). Administration of oestradiol in female rodents increases the expression of tryptophan hydroxylase-2, an enzyme important in the synthesis of serotonin (4). Furthermore, in ER $\beta$ knockout mice, serotonin levels are decreased in brain areas believed to be important in mood regulation (4). In addition, monoamine oxidase concentrations, which are important for the enzymatic degradation of neurotransmitters in the synaptic cleft, can be decreased by oestrogen. Progesterone has the opposite effect on monoamine oxidase concentration levels (3). Although the effects of sex steroids on neuronal transmission are likely to differ between humans and rodents, animal studies confirm that sex steroids regulate serotonin receptor expression and can affect mood (90).

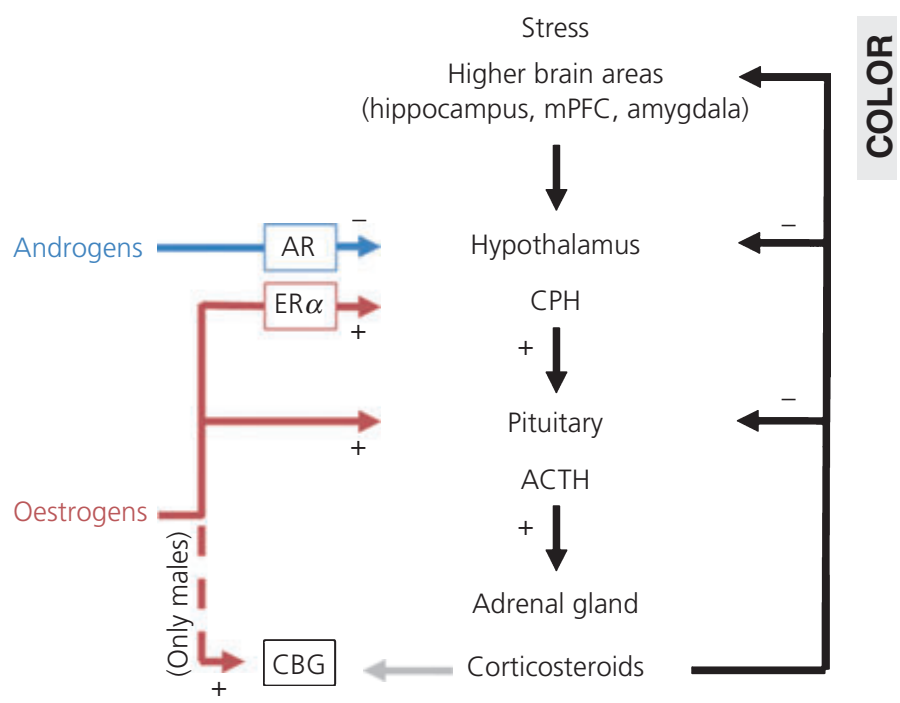

Fig. 2. Sex differences in adolescent vulnerability to depression. ACTH, adrenocorticotrophic hormone; $A R$, androgen receptor; $C B G$, corticosteroidbinding globulin; $\mathrm{CPH}$, ???; $\mathrm{ER}$, oestrogen receptor; $\mathrm{mPFC}$, medial prefrontal $\mathbf{6}$ cortex. 


\section{Conclusions}

Various psychological, environmental, social and biological factors are involved in the aetiology of depression and interact in a complex pattern. Sex steroids play a crucial role in modulating brain morphology and functioning. During adolescence, the brain has to adjust to increased sex steroid levels and (especially in girls) to cyclic fluctuations in these levels. The changes in sex steroid levels induce alterations in neurotransmitter systems, such as the serotonergic system, and alterations in sex steroid levels and neurotransmitters systems can potently, and lastingly, affect mood and behaviour. As such, changes in sex steroid levels occurring during adolescence may increase the vulnerability to depression.

Especially the effect of sex steroids on the maturing HPA axis makes girls more sensitive to the effects of stress, whereas androgens appear to play a protective role in boys. Together with a genetic predisposition and/or psychosocial factors, this may trigger an easier onset of depression in girls. Thus, the greater prevalence of depression in adolescent girls likely results from a combination of profound hormonal changes, fluctuations in hormone levels and psychosocial factors (Fig. 2). Furthermore, we have described the possibility that sex differences in brain structure and function (e.g. sex differences in neurotransmitter systems or in brain areas important for the stress response) contribute to the sex difference in the emergence of depression. Whether similar underlying mechanisms are involved in the emergence of sex differences in human psychopathology remains to be studied, and longitudinal human studies in both sexes are required to elucidate a relation between biological changes during adolescence and the emergence of psychopathology. Careful repetitive monitoring of the developmental stage, cognitive and behavioural variables and hormone levels in a large group of young participants might help to resolve this question. Although new imaging techniques allow the study of alterations in brain volume and grey and white matter concentrations, they might not be sensitive enough to detect sex steroid-dependent alterations in neuronal development because sex steroids are considered to affect the brain in very subtle ways (e.g. on the cellular level) that are beyond the resolution and detection level of such approaches.

Animal research can be a valuable tool to clarify the role of sex steroids in brain development and in the modulation of neurotransmission and HPA axis regulation. By contrast, establishing the influence of these processes on mood is more difficult to study in an animal model, and it thus remains challenging to translate these findings to the human situation. One of the practical difficulties in doing so is the fact that many animal models of depression have been developed in male rodents and therefore they may not be appropriate to model depression in females. By contrast to the pronounced sex difference in human depression in female rodents, depression-like behaviour is less evident than in male rodents. For example, in the learned helplessness paradigm, a commonly used method to investigate depression-like behaviour in rodents, female rats display less helplessness behaviour than male rats and gonadoectomy in either males or females does not reverse this sex-specific behaviour $(93,94)$. By contrast, chronic mild stress paradigms have been described to induce more depressive-like behaviour in female compared to male rodents (95). Thus, the strengths and limitations of each animal model of depression need to be considered to allow the effective use of such a model for studying sex differences in depression.

A better understanding of the interplay of adolescent brain development and the modulating effects of sex steroids is needed to explain how sex differences in the incidence of depression emerge during adolescence. This will be of great relevance for individual patients and society and may also help the development of new treatment strategies for these devastating disorders.

7 Received 18 October 2010,

revised 8 March 2011,

accepted 12 March 2011

\section{References}

1 Allin S, Baris E, Farrington J, Guisset A, Jowett M, Koller T, Kutzin J, Lazarus J, Lear J, Loyola E, Mitis E, Nosikov A, Pellny M, Permanand G, Schiotz M, Sedgley M, Simpson S, Veillard J. The European Health Report 2009: Health and Health Systems (WHO). 2009.

2 Nolen-Hoeksema S, Girgus JS. The emergence of gender differences in depression during adolescence. Psychol Bull 1994; 115: 424-443.

3 Frackiewicz EJ, Sramek JJ, Cutler NR. Gender differences in depression and antidepressant pharmacokinetics and adverse events. Ann Pharmacother 2000; 34: 80-88.

4 Solomon MB, Herman JP. Sex differences in psychopathology: of gonads, adrenals and mental illness. Physiol Behav 2009; 97: 250-258.

5 Joffe $H$, Cohen LS. Estrogen, serotonin, and mood disturbance: where is the therapeutic bridge? Biol Psychiatry 1998; 44: 798-811.

6 Kessler RC, McGonagle KA, Swartz M, Blazer DG, Nelson CB. Sex and depression in the National Comorbidity Survey. I: lifetime prevalence, chronicity and recurrence. J Affect Disord 1993; 29: 85-96.

7 Becker JB, Monteggia LM, Perrot-Sinal TS, Romeo RD, Taylor JR, Yehuda $\mathrm{R}$, Bale TL. Stress and disease: is being female a predisposing factor? J Neurosci 2007; 27: 11851-11855.

8 Lenroot RK, Giedd JN. Sex differences in the adolescent brain. Brain Cogn 2010; 72: 46-55

9 Greydanus DE, Bacopoulou F, Tsalamanios E. Suicide in adolescents: a worldwide preventable tragedy. Keio J Med 2009; 58: 95-102.

10 Hazell P. Depression in children and adolescents. Clin Evid (Online) 2009: ????-????

11 Vitiello B. Treatment of adolescent depression: what we have come to know. Depress Anxiety 2009; 26: 393-395.

12 Leon AC. The revised warning for antidepressants and suicidality: unveiling the black box of statistical analyses. Am J Psychiatry 2007; 164: 1786-1789

13 Ansorge MS, Zhou M, Lira A, Hen R, Gingrich JA. Early-life blockade of the $5-\mathrm{HT}$ transporter alters emotional behavior in adult mice. Science 2004; 306: 879-881.

14 Norcross M, Mathur P, Enoch AJ, Karlsson RM, Brigman JL, Cameron HA, Harvey-White J, Holmes A. Effects of adolescent fluoxetine treatment on fear-, anxiety- or stress-related behaviors in C57BL/6J or BALB/CJ mice. Psychopharmacology (Berl) 2008; 200: 413-424.

15 Hodes GE, Yang L, Van KJ, Santollo J, Shors TJ. Prozac during puberty: distinctive effects on neurogenesis as a function of age and sex. Neuroscience 2009; 163: 609-617. 
16 Hodes GE, Hill-Smith TE, Suckow RF, Cooper TB, Lucki I. Sex-specific effects of chronic fluoxetine treatment on neuroplasticity and pharmacokinetics in mice. J Pharmacol Exp Ther 2010; 332: 266-273.

17 Bennett DS, Ambrosini PJ, Kudes D, Metz C, Rabinovich H. Gender differences in adolescent depression: do symptoms differ for boys and girls? J Affect Disord 2005; 89: 35-44.

18 Dahl RE. Adolescent brain development: a period of vulnerabilities and opportunities. Keynote address. Ann NY Acad Sci 2004; 1021: 1-22.

19 Neufang S, Specht K, Hausmann M, Gunturkun O, Herpertz-Dahlmann B, Fink GR, Konrad K. Sex differences and the impact of steroid hormones on the developing human brain. Cereb Cortex 2009; 19: 464-473.

20 Buchanan CM, Eccles JS, Becker JB. Are adolescents the victims of raging hormones: evidence for activational effects of hormones on moods and behavior at adolescence. Psychol Bull 1992; 111: 62-107.

21 Giedd JN, Clasen LS, Lenroot R, Greenstein D, Wallace GL, Ordaz S, Molloy EA, Blumenthal JD, Tossell JW, Stayer C, Samango-Sprouse CA, Shen D, Davatzikos C, Merke D, Chrousos GP. Puberty-related influences on brain development. Mol Cell Endocrinol 2006; 254-255: 154-162.

22 Peper JS, Brouwer RM, Schnack HG, van Baal GC, van LM, van den Berg SM, Delemarre-Van de Waal HA, Boomsma DI, Kahn RS, Hulshoff Pol HE. Sex steroids and brain structure in pubertal boys and girls. Psychoneuroendocrinology 2009; 34: 332-342.

23 Giedd JN, Blumenthal J, Jeffries NO, Castellanos FX, Liu H, Zijdenbos A, Paus T, Evans AC, Rapoport JL. Brain development during childhood and adolescence: a longitudinal MRI study. Nat Neurosci 1999; 2: 861-863.

24 Bao AM, Swaab DF. Sex differences in the brain, behavior, and neuropsychiatric disorders. Neuroscientist 2010; 16: 550-565.

25 Schwarz JM, McCarthy MM. Steroid-induced sexual differentiation of the developing brain: multiple pathways, one goal. J Neurochem 2008; 105: 1561-1572.

26 Murakami S, Arai Y. Neuronal death in the developing sexually dimorphic periventricular nucleus of the preoptic area in the female rat: effect of neonatal androgen treatment. Neurosci Lett 1989; 102: 185-190.

27 Nordeen EJ, Nordeen KW, Sengelaub DR, Arnold AP. Androgens prevent normally occurring cell death in a sexually dimorphic spinal nucleus. Science 1985; 229: 671-673.

28 Zhou JN, Hofman MA, Gooren $\sqcup$, Swaab DF. A sex difference in the human brain and its relation to transsexuality. Nature 1995; 378: 68-70.

29 Phoenix CH, Goy RW, Gerall AA, Young WC. Organizing action of prenatally administered testosterone propionate on the tissues mediating mating behavior in the female guinea pig. Endocrinology 1959; 65: 369382.

30 Schulz KM, Molenda-Figueira HA, Sisk CL. Back to the future: the organizational-activational hypothesis adapted to puberty and adolescence. Horm Behav 2009; 55: 597-604.

31 Manson JE. Prenatal exposure to sex steroid hormones and behavioral/cognitive outcomes. Metabolism 2008; 57(Suppl. 2): S16-S21.

32 Bakker J, Baum MJ. Role for estradiol in female-typical brain and behavioral sexual differentiation. Front Neuroendocrinol 2008; 29: 1-16.

33 Hines $M$, Allen LS, Gorski RA. Sex differences in subregions of the medial nucleus of the amygdala and the bed nucleus of the stria terminalis of the rat. Brain Res 1992; 579: 321-326.

34 Ahmed El, Zehr JL, Schulz KM, Lorenz BH, DonCarlos LL, Sisk CL. Pubertal hormones modulate the addition of new cells to sexually dimorphic brain regions. Nat Neurosci 2008; 11: 995-997.

35 Schulz KM, Sisk CL. Pubertal hormones, the adolescent brain, and the maturation of social behaviors: lessons from the Syrian hamster. Mol Cell Endocrinol 2006; 254-255: 120-126.

36 Sisk CL, Zehr JL. Pubertal hormones organize the adolescent brain and behavior. Front Neuroendocrinol 2005; 26: 163-174.

37 Wallen K. Hormonal influences on sexually differentiated behavior in nonhuman primates. Front Neuroendocrinol 2005; 26: 7-26.
38 Tobet S, Knoll JG, Hartshorn C, Aurand E, Stratton M, Kumar P, Searcy B, McClellan K. Brain sex differences and hormone influences: a moving experience? J Neuroendocrinol 2009; 21: 387-392.

39 Zehr JL, Nichols LR, Schulz KM, Sisk CL. Adolescent development of neuron structure in dentate gyrus granule cells of male Syrian hamsters. Dev Neurobiol 2008; 68: 1517-1526.

40 Markham JA, Morris JR, Juraska JM. Neuron number decreases in the rat ventral, but not dorsal, medial prefrontal cortex between adolescence and adulthood. Neuroscience 2007; 144: 961-968.

41 Schildkraut JJ. The catecholamine hypothesis of affective disorders: a review of supporting evidence. Am J Psychiatry 1965; 122: 509-522.

42 Steiner $M$, Dunn E, Born L. Hormones and mood: from menarche to menopause and beyond. J Affect Disord 2003; 74: 67-83.

43 Hughes CW, Petty F, Sheikha S, Kramer GL. Whole-blood serotonin in children and adolescents with mood and behavior disorders. Psychiatry Res 1996; 65: 79-95.

44 Castren E. Is mood chemistry? Nat Rev Neurosci 2005; 6: 241-246.

45 Czeh B, Lucassen PJ. What causes the hippocampal volume decrease in depression? Are neurogenesis, glial changes and apoptosis implicated? Eur Arch Psychiatry Clin Neurosci 2007; 257: 250-260.

46 Lucassen PJ, Meerlo P, Naylor AS, van Dam AM, Dayer AG, Fuchs E, Oomen $C A, C z e h$ B. Regulation of adult neurogenesis by stress, sleep disruption, exercise and inflammation: implications for depression and antidepressant action. Eur Neuropsychopharmacol 2010; 20: 1-17.

47 Romeo RD, McEwen BS. Stress and the adolescent brain. Ann NY Acad Sci 2006; 1094: 202-214.

48 Swaab DF, Bao AM, Lucassen PJ. The stress system in the human brain in depression and neurodegeneration. Ageing Res Rev 2005; 4: 141-194.

49 Raadsheer FC, van Heerikhuize JJ, Lucassen PJ, Hoogendijk WJ, Tilders FJ, Swaab DF. Corticotropin-releasing hormone mRNA levels in the paraventricular nucleus of patients with Alzheimer's disease and depression. Am J Psychiatry 1995; 152: 1372-1376.

50 Lucassen PJ, Muller MB, Holsboer F, Bauer J, Holtrop A, Wouda J, Hoogendijk WJ, De Kloet ER, Swaab DF. Hippocampal apoptosis in major depression is a minor event and absent from subareas at risk for glucocorticoid overexposure. Am J Pathol 2001; 158: 453-468.

51 Muller MB, Lucassen PJ, Yassouridis A, Hoogendijk WJ, Holsboer F, Swaab DF. Neither major depression nor glucocorticoid treatment affects the cellular integrity of the human hippocampus. Eur J Neurosci 2001; 14: 1603-1612.

52 Boldrini M, Underwood MD, Hen R, Rosoklija GB, Dwork AJ, John MJ, Arango $V$. Antidepressants increase neural progenitor cells in the human hippocampus. Neuropsychopharmacology 2009; 34: 2376-2389.

53 Lucassen PJ, Stumpel MW, Wang Q, Aronica E. Decreased numbers of progenitor cells but no response to antidepressant drugs in the hippocampus of elderly depressed patients. Neuropharmacology 2010; 58: 940-949.

54 Campbell S, Marriott M, Nahmias C, MacQueen GM. Lower hippocampal volume in patients suffering from depression: a meta-analysis. Am J Psychiatry 2004; 161: 598-607.

55 Axelson DA, Doraiswamy PM, McDonald WM, Boyko OB, Tupler LA, Patterson $\sqcup$, Nemeroff CB, Ellinwood EH Jr, Krishnan KR. Hypercortisolemia and hippocampal changes in depression. Psychiatry Res 1993; 47: 163173.

56 Bremner JD, Narayan M, Anderson ER, Staib LH, Miller HL, Charney DS. Hippocampal volume reduction in major depression. Am J Psychiatry 2000; 157: 115-118.

57 Janssen J, Hulshoff Pol HE, Lampe IK, Schnack HG, de Leeuw FE, Kahn RS, Heeren TJ. Hippocampal changes and white matter lesions in earlyonset depression. Biol Psychiatry 2004; 56: 825-831.

58 Videbech P, Ravnkilde B. Hippocampal volume and depression: a metaanalysis of MRI studies. Am J Psychiatry 2004; 161: 1957-1966. 
59 Chen MC, Hamilton JP, Gotlib IH. Decreased hippocampal volume in healthy girls at risk of depression. Arch Gen Psychiatry 2010; 67: 270276.

60 Oomen CA, Soeters H, Audureau N, Vermunt L, van Hasselt FN, Manders $E M$, Joels $M$, Lucassen PJ, Krugers $H$. Severe early life stress hampers spatial learning and neurogenesis, but improves hippocampal synaptic plasticity and emotional learning under high-stress conditions in adulthood. J Neurosci 2010; 30: 6635-6645.

61 Oomen CA, Soeters H, Audureau N, Vermunt L, van Hasselt FN, Manders EMM, Joëls $M$, Krugers $H$, Lucassen PJ. Early maternal deprivation affects dentate gyrus structure and emotional learning in adult females. Psychopharmacology 2011; 214: 249-260.

62 Vythilingam $M$, Heim $C$, Newport J, Miller AH, Anderson E, Bronen R, Brummer M, Staib L, Vermetten E, Charney DS, Nemeroff CB, Bremner JD. Childhood trauma associated with smaller hippocampal volume in women with major depression. Am J Psychiatry 2002; 159: 2072-2080.

63 Heine VM, Maslam S, Zareno J, Joels M, Lucassen PJ. Suppressed proliferation and apoptotic changes in the rat dentate gyrus after acute and chronic stress are reversible. Eur J Neurosci 2004; 19: 131-144.

64 Leventopoulos M, Ruedi-Bettschen D, Knuesel I, Feldon J, Pryce CR, Opacka-Juffry J. Long-term effects of early life deprivation on brain glia in Fischer rats. Brain Res 2007; 1142: 119-126.

65 Fabricius K, Wortwein G, Pakkenberg B. The impact of maternal separation on adult mouse behaviour and on the total neuron number in the mouse hippocampus. Brain Struct Funct 2008; 212: 403-416.

66 Huot RL, Plotsky PM, Lenox RH, McNamara RK. Neonatal maternal separation reduces hippocampal mossy fiber density in adult Long Evans rats. Brain Res 2002; 950: 52-63.

67 Aisa B, Elizalde N, Tordera R, Lasheras B, Del RJ, Ramirez MJ. Effects of neonatal stress on markers of synaptic plasticity in the hippocampus: implications for spatial memory. Hippocampus 2009; 19: 1222-1231.

68 Mirescu C, Peters JD, Gould E. Early life experience alters response of adult neurogenesis to stress. Nat Neurosci 2004; 7: 841-846.

69 Oomen CA, Girardi CE, Cahyadi R, Verbeek EC, Krugers H, Joels M, Lucassen PJ. Opposite effects of early maternal deprivation on neurogenesis in male versus female rats. PLOS ONE 2009; 4: e3675.

70 Schmitz C, Rhodes ME, Bludau M, Kaplan S, Ong P, Ueffing I, Vehoff J, Korr $H_{1}$ Frye CA. Depression: reduced number of granule cells in the hippocampus of female, but not male, rats due to prenatal restraint stress. Mol Psychiatry 2002; 7: 810-813.

71 Weinstock M. Gender differences in the effects of prenatal stress on brain development and behaviour. Neurochem Res 2007; 32: 17301740.

72 Levine S, Chevalier JA, Korchin SJ. The effects of early shock and handling on later avoidance learning. J Pers 1956; 24: 475-493.

73 Lehmann J, Russig H, Feldon J, Pryce CR. Effect of a single maternal separation at different pup ages on the corticosterone stress response in adult and aged rats. Pharmacol Biochem Behav 2002; 73: 141-145.

74 Plotsky PM, Meaney MJ. Early, postnatal experience alters hypothalamic corticotropin-releasing factor (CRF) mRNA, median eminence CRF content and stress-induced release in adult rats. Brain Res Mol Brain Res 1993; 18: 195-200.

75 Pryce $C R$, Feldon J. Long-term neurobehavioural impact of the postnatal environment in rats: manipulations, effects and mediating mechanisms. Neurosci Biobehav Rev 2003; 27: 57-71.
76 Rao U, Chen LA, Bidesi AS, Shad MU, Thomas MA, Hammen CL. Hippocampal changes associated with early-life adversity and vulnerability to depression. Biol Psychiatry 2010; 67: 357-364.

77 McEwen BS. Early life influences on life-long patterns of behavior and health. Ment Retard Dev Disabil Res Rev 2003; 9: 149-154.

78 Heim C, Nemeroff CB. The role of childhood trauma in the neurobiology of mood and anxiety disorders: preclinical and clinical studies. Biol Psychiatry 2001; 49: 1023-1039.

79 Seeman MV. Psychopathology in women and men: focus on female hormones. Am J Psychiatry 1997; 154: 1641-1647.

80 Romeo RD. Adolescence: a central event in shaping stress reactivity. Dev Psychobiol 2010; 52: 244-253.

81 Sapolsky RM, Meaney MJ. Maturation of the adrenocortical stress response: neuroendocrine control mechanisms and the stress hyporesponsive period. Brain Res 1986; 396: 64-76.

82 Romeo RD, Lee SJ, McEwen BS. Differential stress reactivity in intact and ovariectomized prepubertal and adult female rats. Neuroendocrinology 2004; 80: 387-393.

83 Romeo RD, Lee SJ, Chhua N, McPherson CR, McEwen BS. Testosterone cannot activate an adult-like stress response in prepubertal male rats. Neuroendocrinology 2004; 79: 125-132.

84 Doremus-Fitzwater TL, Varlinskaya El, Spear LP. Social and non-social anxiety in adolescent and adult rats after repeated restraint. Physiol Behav 2009; 97: 484-494.

85 Tsoory $M$, Richter-Levin G. Learning under stress in the adult rat is differentially affected by 'juvenile' or 'adolescent' stress. Int J Neuropsychopharmacol 2006; 9: 713-728.

86 Barha CK, Brummelte S, Lieblich SE, Galea LA. Chronic restraint stress in adolescence differentially influences hypothalamic-pituitary-adrenal axis function and adult hippocampal neurogenesis in male and female rats. Hippocampus 2010; ????: ????-????.

87 McCormick CM, Mathews IZ. HPA function in adolescence: role of sex hormones in its regulation and the enduring consequences of exposure to stressors. Pharmacol Biochem Behav 2007; 86: 220-233.

88 Shors TJ, Chua C, Falduto J. Sex differences and opposite effects of stress on dendritic spine density in the male versus female hippocampus. J Neurosci 2001; 21: 6292-6297.

89 Dalla C, Whetstone AS, Hodes GE, Shors TJ. Stressful experience has opposite effects on dendritic spines in the hippocampus of cycling versus masculinized females. Neurosci Lett 2009; 449: 52-56.

90 Rubinow DR, Schmidt PJ, Roca CA. Estrogen-serotonin interactions: implications for affective regulation. Biol Psychiatry 1998; 44: 839-850.

91 Toufexis D. Region- and sex-specific modulation of anxiety behaviours in the rat. J Neuroendocrinol 2007; 19: 461-473.

92 Warren MP, Brooks-Gunn J. Mood and behavior at adolescence: evidence for hormonal factors. J Clin Endocrinol Metab 1989; 69: 77-83.

93 Dalla C, Edgecomb C, Whetstone AS, Shors TJ. Females do not express learned helplessness like males do. Neuropsychopharmacology 2008; 33: 1559-1569.

94 Shors TJ, Mathew J, Sisti HM, Edgecomb C, Beckoff S, Dalla C. Neurogenesis and helplessness are mediated by controllability in males but not in females. Biol Psychiatry 2007; 62: 487-495.

95 Dalla C, Antoniou K, Drossopoulou G, Xagoraris M, Kokras N, Sfikakis A, Papadopoulou-Daifoti Z. Chronic mild stress impact: are females more vulnerable? Neuroscience 2005; 135: 703-714. 


\section{Author Query Form}

Journal: $\quad$ JNE

Article: $\quad 2125$

Dear Author,

During the copy-editing of your paper, the following queries arose. Please respond to these by marking up your proofs with the necessary changes/additions. Please write your answers on the query sheet if there is insufficient space on the page proofs. Please write clearly and follow the conventions shown on the attached corrections sheet. If returning the proof by fax do not write too close to the paper's edge. Please remember that illegible mark-ups may delay publication.

Many thanks for your assistance.

\begin{tabular}{|c|c|c|}
\hline Query reference & Query & Remarks \\
\hline 01 & $\begin{array}{l}\text { AUTHOR: A running head short title was not supplied; please check if this one } \\
\text { is suitable and, if not, please supply a short title of up to } 40 \text { characters that } \\
\text { can be used instead. }\end{array}$ & \\
\hline 02 & AUTHOR: Please provide publisher's name and location for reference [1]. & \\
\hline 03 & AUTHOR: Please provide the page range for reference [10]. & \\
\hline 04 & $\begin{array}{l}\text { AUTHOR: Please provide the volume number and page range for reference } \\
\text { [86]. }\end{array}$ & \\
\hline 05 & $\begin{array}{l}\text { AUTHOR: Please make reference in the legend to parts }(A) \text { and }(B) \text { appearing } \\
\text { in the artwork to Figure } 1 .\end{array}$ & \\
\hline 06 & AUTHOR: Please define 'CPH'. & \\
\hline 07 & AUTHOR:Would you like to acknowledge who helped to bring out the paper? & \\
\hline
\end{tabular}




\section{USING E-ANNOTATION TOOLS FOR ELECTRONIC PROOF CORRECTION}

\section{Required Software}

Adobe Acrobat Professional or Acrobat Reader (version 7.0 or above) is required to e-annotate PDFs. Acrobat 8 Reader is a free download: http://www.adobe.com/products/acrobat/readstep2.html

Once you have Acrobat Reader 8 on your PC and open the proof, you will see the Commenting Toolbar (if it does not appear automatically go to Tools>Commenting>Commenting Toolbar). The Commenting Toolbar looks like this:

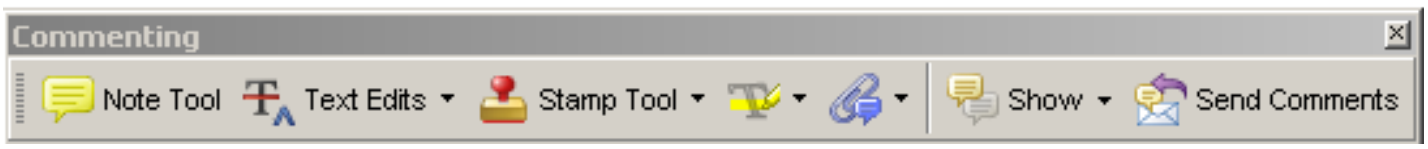

If you experience problems annotating files in Adobe Acrobat Reader 9 then you may need to change a preference setting in order to edit.

In the "Documents" category under "Edit - Preferences", please select the category 'Documents' and change the setting "PDF/A mode:" to "Never".

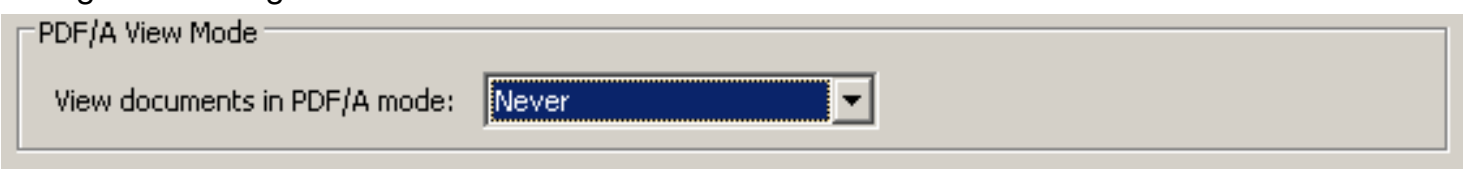

\section{Note Tool - For making notes at specific points in the text}

Marks a point on the paper where a note or question needs to be addressed.

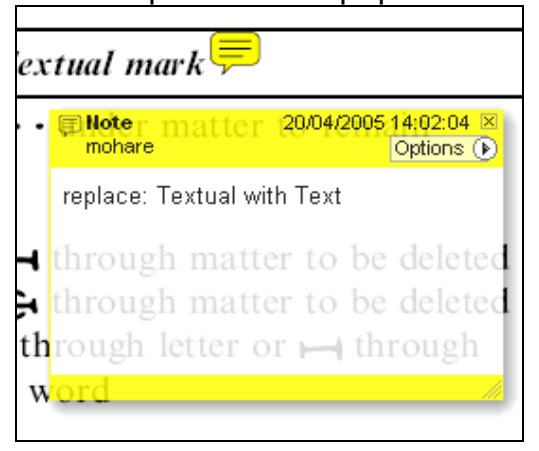

How to use it:

1. Right click into area of either inserted text or relevance to note

2. Select Add Note and a yellow speech bubble symbol and text box will appear

3. Type comment into the text box

4. Click the $X$ in the top right hand corner of the note box to close.

Replacement text tool - For deleting one word/section of text and replacing it

Strikes red line through text and opens up a replacement text box.

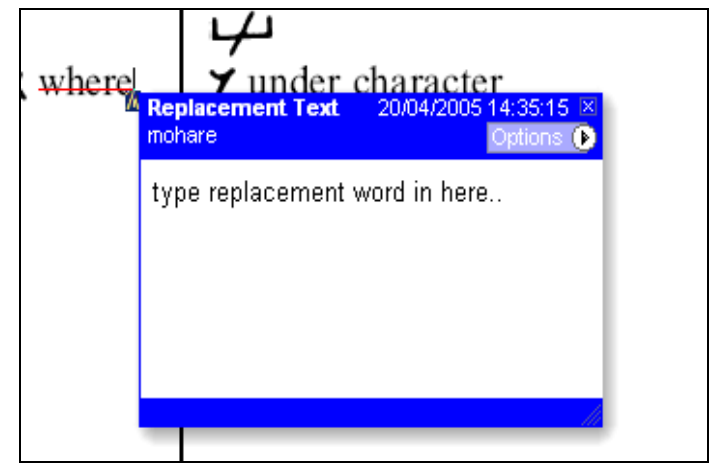

\section{How to use it:}

1. Select cursor from toolbar

2. Highlight word or sentence

3. Right click

4. Select Replace Text (Comment) option

5. Type replacement text in blue box

6. Click outside of the blue box to close

Cross out text tool - For deleting text when there is nothing to replace selection Strikes through text in a red line.

\begin{tabular}{|l|}
\hline substitute part of one or \\
more word(s) \\
Change to italies \\
Change to capitals \\
Change to small capitals \\
\hline
\end{tabular}
How to use it:
1. Select cursor from toolbar
2. Highlight word or sentence
3. Right click
4. Select Cross Out Text 


\section{(W)WILEY-BLACKWELL}

Approved tool - For approving a proof and that no corrections at all are required.

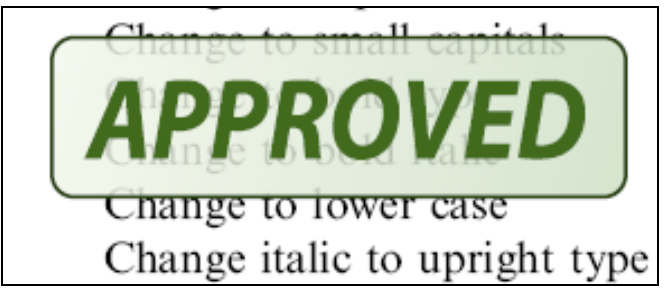

How to use it:

1. Click on the Stamp Tool in the toolbar

2. Select the Approved rubber stamp from the 'standard business' selection

3. Click on the text where you want to rubber stamp to appear (usually first page)

Highlight tool — For highlighting selection that should be changed to bold or italic. Highlights text in yellow and opens up a text box.

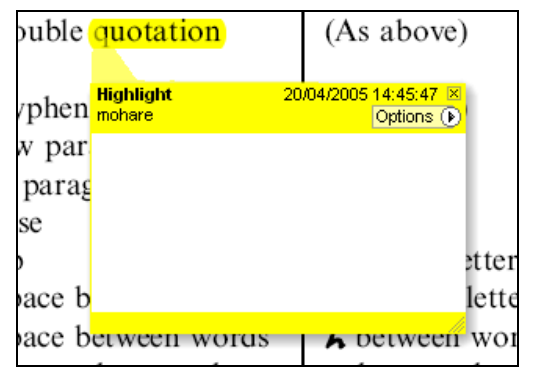

How to use it:

1. Select Highlighter Tool from the commenting toolbar

2. Highlight the desired text

3. Add a note detailing the required change

Attach File Tool - For inserting large amounts of text or replacement figures as a files. Inserts symbol and speech bubble where a file has been inserted.

\section{matter to be changed matter to matter to be changed matter to be changed} How to use it:

1. Click on paperclip icon in the commenting toolbar

2. Click where you want to insert the attachment

3. Select the saved file from your PC/network

4. Select appearance of icon (paperclip, graph, attachment or tag) and close

\section{Pencil tool - For circling parts of figures or making freeform marks}

Creates freeform shapes with a pencil tool. Particularly with graphics within the proof it may be useful to use the Drawing Markups toolbar. These tools allow you to draw circles, lines and comment on these marks.

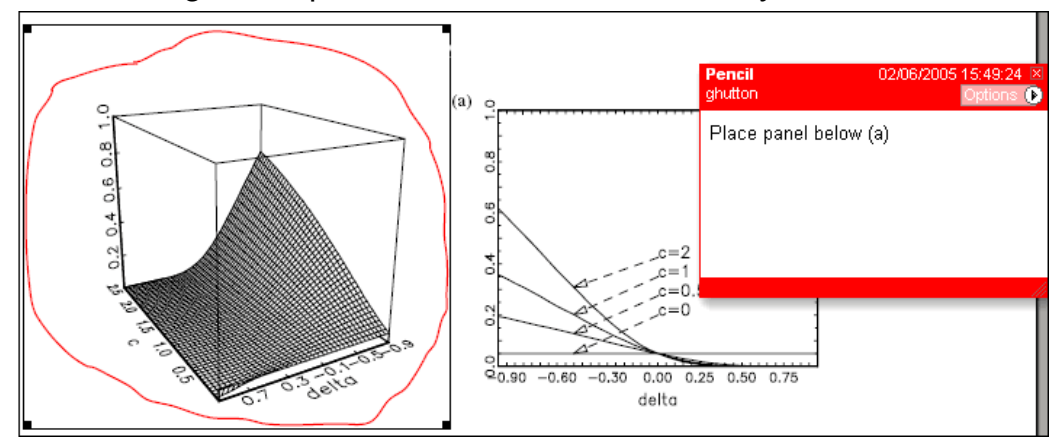

How to use it:

1. Select Tools $>$ Drawing Markups $>$ Pencil Tool

2. Draw with the cursor

3. Multiple pieces of pencil annotation can be grouped together

4. Once finished, move the cursor over the shape until an arrowhead appears and right click

5. Select Open Pop-Up Note and type in a details of required change

6. Click the $\mathrm{X}$ in the top right hand corner of the note box to close. 


\section{WILEY-BLACKWELL}

Help

For further information on how to annotate proofs click on the Help button to activate a list of instructions:

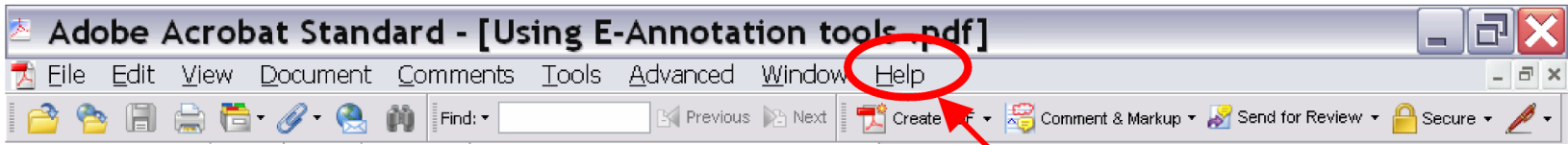

